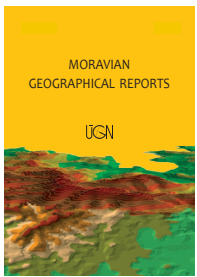

MORAVIAN GEOGRAPHICAL REPORTS

\title{
Anytime? Anywhere? The seasonality of flight offers in Central Europe
}

\author{
Stanislav KRAFT a *, Denisa HAVLÍKOVÁ a
}

\begin{abstract}
Air transport can be considered as the most dynamic transport mode during recent decades. It is an important but also responsive indicator of global social, economic, political and cultural cooperation in different areas. For this reason, air transport is a unique source of various aspects of international relations. The principal goal of this study is an analysis of seasonality in the offer of flights in Central Europe during 2014, considering the different positions and functions of the airports within the air transport system. Ten airports from the Central European region are monitored in the analysis in terms of fluctuations in flight offers and offered destinations. A synthesis of these patterns is presented as a typology of the surveyed airports using the Ossan triangle. This paper clearly shows the different patterns of the spatial and temporal organization of air transport in Central Europe.
\end{abstract}

Key words: air transport, seasonality, typology of airports, Central Europe

Article history: Received 19 September 2016; Accepted 15 December 2016; Published 30 December 2016

\section{Introduction}

The rapid development of air transport since the 1970s represents one of the most important signs of the development of modern transport systems in the postindustrial period. It is also considered a significant sign of globalisation processes, as the development of air transport has enabled efficient and rapid very long-range exchanges of persons and goods (Debbage, 1994; Goetz and Graham, 2004). Since the 1970s, continuous growth has been observed in the number of transported persons and goods, growth in transport performance, as well as in the average distance covered by air transport. Such recent abrupt growth was only hindered, albeit temporarily, by recent economic crises, especially recognised in 1997/1998 and 2008 (Dobruszkes and Van Hamme, 2011). Generally speaking, the economic crises had a stronger effect on the volume of transport in goods than in the transport of persons. Apart from those general trends, air transport has seen major organisational changes that have been caused by its deregulation and liberalisation. The joint effects of these changes include the development of airline hubs, the concentration of flight connections by major airlines, the development of airline alliances, as well as the development of low-cost carriers (LCCs) and secondary airports (Thompson, 2002). As such, the deregulation of air transport can be recognised as the most important change in the spatial organisation of air transport: in fact, Alderighi et al. (2005) claim that such changes were influenced by a number of spatial causes and effects.
Central Europe represents a specific area in the development of air transport. It consists of well-developed countries with a high share of air transport (Germany, Austria), as well as former socialist countries with recent rapid growth of air transport (Poland, Czech Republic, Slovakia and Hungary). The latter states witnessed many years of control by the communist regime: air transport was not a priority transport mode, which was reflected in its not being particularly important. The dramatic political, economic, social and cultural changes after the fall of the Iron Curtain in 1989 and 1990, however, did highlight the role of air transport in the transport market. The principal reasons included the opportunity to travel to Western countries, the growth of international tourism, the increase in available income and the integration into international economic structures. The accession of these countries to the European Union in 2004 was the final expansion of the liberalised air transport market to Central Europe (Jankiewicz and Huderek-Glapska, 2016): hence, air transport registered a very dynamic development in the number of transported persons and goods (Grenčíková et al., 2011). The air transport market in Central Europe also became attractive to foreign airlines, although several authors, such as Dobruszkes (2009), claim that the area was a rather secondary market for those airlines. The arrival of major competing airlines and LCCs in this market did bring problems to some of the traditional national airlines. This is documented by the bankruptcy of the Hungarian flag carrier Malév, which went out of business in 2012.

\footnotetext{
${ }^{a}$ Department of Geography, University of South Bohemia in České Budějovice, Czech Republic (*corresponding author: S. Kraft, email: kraft@pf.jcu.cz)
} 
The Central European air transport market currently shows rather considerable dynamics which are the result of its geopolitical location, recent history and contemporary integration tendencies. The development of smaller and secondary airports in the region delivered direct consequences in the better accessibility of air transport; on the other hand, it did cause major fluctuations in the seasonal offer of flights. The fluctuations are typically related to the high season of tourism (Reichard, 1988; Wensveen, 2007). Therefore, some airports tended to see considerable change in the number of flights and the structure of carriers, as well as offers of available destinations during the year. For example, smaller airports usually show a higher frequency of flights in the summer months than in other seasons. Those trends, however, are also recognised in major airports where both regular and charter flights are made.

The overall topic is quite complicated as it results from an accumulation of several conditions (e.g. the position and function of the airport, the strategies adopted by individual airports and carriers, etc.). The topic of seasonal fluctuation in the offer of flights is therefore one of the major research areas from a geographic point of view (Papatheodorou, 2002; Page, 2005). This discussion indicates that Central Europe represents a unique space for research on changes in air transport, as the processes occurred quite recently and rather very quickly: general discussions are presented by Pucher (1999) and Jankiewicz and Huderek-Glapska (2016).

This paper has several aims. It focuses on an examination of the offer of air transport in selected airports in the Central European region. The principal goal is an analysis of seasonality in the offer of flights during 2014 considering the different positions and functions of the airports within the air transport system. The subject airports are FrankfurtHahn (HHN), Rostock-Laage (RLG), Salzburg (SZG), Prague (PRG), Pardubice (PED), Brno (BRQ), Vienna (VIE), Bratislava (BTS), Warsaw (WAW) and Debrecen (DEB). The authors also focus on changes in the accessibility of destinations throughout the year, as well as structural characteristics of the airports from the perspective of services by low-cost and traditional network carriers. The monitored fluctuations assist in the interpretation of the differences and fluctuations in the seasonal offer of flights from the airports. The article is a contribution to the current state of knowledge on the impact of organisational changes in air transport on individual airports and regions.

As the research explores Central European countries, it also monitors the current organisation of air transport in the capitalist and former socialist countries in the region. The current situation is seen as part of the overall postsocialist transformations of the region, which have affected the development of transport after 1990, as well as building new relationships between Western and Central Europe (Ivy, 1995). The findings of the study therefore can be useful for geographers, for regional economists, transport scientists, spatial planners, tourism experts, environmentalists and many others.

The structure of this article is as follows: the general introduction is followed by discussions of the theoretical background. The authors primarily focus on contemporary changes in the configuration of major airlines and LCCs. Other topics that are explored are the specific developments of air transport in Central Europe and the relationships between air transport and tourism. The analytical section presents the principal findings of the study, focusing on an analysis of seasonality in the offer of flights in selected airports in Central Europe. Changes in the accessibility of destinations during the year and in the structure of flight offers from the perspective of type of carrier are also discussed. The airports have been selected to reflect the natural differences in their functions in the air transport system (major airline hubs, regional airports, etc.). Seasonal fluctuations in the offer of air transport and the corresponding changes in the accessibility of final destinations are the basics for a typology of the airports in terms of their function in the air transport system. The conclusions present a synthesis of the issues being addressed and recommendations for further research.

\section{Current changes in the organisation of air transport and its spatial impacts}

In the past five decades, the air transport system has undergone major changes which have affected its current spatial organisation. These changes have been caused primarily by the deregulation and liberalisation of air transport. The deregulation was typical mainly for the United States where the goal of deregulation was the elimination of regulation controls (e.g. ticket prices). The liberalisation (typical for the European Union) of air transport represents a number of measures that permit airlines to offer flights to any destination, in any country and at any price (Seidenglanz, 2010). This also affected by a major change, as prior to deregulation, the air transport market in a country was typically closed and it would be controlled by one flag carrier. Furthermore, flag carriers would receive support from the country's budget. Prior to deregulation, international air transport was for the most part based on the existence of bilateral contracts between individual countries. As flag carriers did not feel any danger from competitors, air transport was rather expensive before deregulation (Burghouwt and Huys, 2003). Gradual deregulation is related to the introduction of freedom to air transport. Currently, nine ICAO freedoms of the air have been defined (e.g. to transport passengers in a foreign country, etc.).

Deregulation of air transport started in the late 1970s in the United States and in the 1990s in the European Union. The gradual enlargement of the European Union also expanded the free air transport market in Europe. As such, the deregulation of air transport delivered a single free air transport market which instigated changes in the spatial configuration of air transport. The free access of carriers to the market caused competition to increase, which in turn delivered higher efficiency and a reduction of prices in air transport. The increased competition did have a number of positive and negative consequences however: in particular, the increased detrimental effects on the environment caused by the higher frequency of air transport (Dobruszkes, 2006). Such effects are critical in stating that in spite of the overall liberalisation and deregulation of the air transport system, it shows some prevailing deficiencies. Dobruszkes argues that the most serious deficiencies include problems in allocating airport time, complicated supervision over airlines, the financial problems of some airlines and airports, and the fact that about $80 \%$ of airlines departing from airports in the European Union are used by one or two carriers.

A general observation can be made that a direct effect of deregulation was the concentration of air transport in hub-and-spoke networks. This is typical for major network carriers who usually possess a large market share. The principle of hub-and-spoke networks uses large airports as the hubs, which act like points where passengers change 
planes on long-range international flights. Thus, the hubs also concentrate on flights from smaller (spoke) airports. Therefore, the hub-and-spoke networks have enabled spatial flexibility of air transport where passengers can fly to any destination from anywhere, even at the expense of having to change planes at a hub airport. Major airlines also further benefit from the fact that this type of network generates considerable savings related to the higher density of traffic at the hub airports. On a global level, the hub-and-spoke system caused a higher concentration of air transport to a small number of airline hubs (in Europe, these include Frankfurt, Paris, London, Amsterdam, etc.).

In turn, these developments contributed to the growing differences in connections between individual parts of the world (Burghouwt, 2007). Core macroregions of the world have a rather higher rate of connection, which leads to strengthening their mutual relations (Derruder and Witlox, 2008). On the other hand, the impact of centralisation of air transport in the world's peripheral regions (especially Africa) has been much lower, contributing to their partial marginalisation. Therefore, air transport has on a global level become a mode that expands coreperiphery polarisation (Goetz and Sutton, 1997). One of the results of the introduction of the hub-and-spoke system is the higher frequency of air transport and higher efficiency of air transport operations from the airlines' perspectives (Dobruszkes, 2009). The advantages of major airlines grew even further when the nationwide hub-and-spoke networks were connected to computerised reservation and loyalty programs (Rodrigue et al., 2013).

Another major sign of deregulation in air transport is the emergence of LCCs, as they are a direct result of the birth of a free market in air transport. LCCs push to maximise their profits by reducing costs and services offered. The essential tools for maximising profit includes the usage for the maximum capacity of planes, absence of in-flight refreshments, fees for any other services, as well as a higher orientation to small regional airports. In particular, their input dwells on the lower fees the airlines are required to pay there. Southwest Airlines in the United States was historically the first company to have introduced the LCCs concept. It served as a model upon which other airlines modified their business strategies. Ireland's Ryanair is an example of this in Europe (Francis et al., 2006). The configuration of the airline networks of LCCs seems to resemble the point-topoint networks, although some LCCs also adopted the huband-spoke networks. The reality, however, is considerably much more complex as LCCs are a highly heterogeneous group of carriers who often differ in their business and spatial strategies. The central point-to-point system has all airports mutually connected, so that passengers can fly from one airport to another directly, without having to change at a hub or getting off their plane at all (Reggiani et al., 2009): passengers value highly the point-to-point flights because they have reduced their overall travel time by removing intermediate landings (Cook and Goodwin, 2008).

The changes mentioned above in the configuration of air transport have also had a considerable impact on society. Not only have the past several decades seen a higher intensity of air transport, they have also witnessed an abrupt development of tourism as a whole. The relationship between the advancement of air transport and tourism is therefore a popular topic of geographic studies (e.g. Page, 2005; Button et al., 1998). The deregulation of air transport and the changes related thereto (especially the price reduction of airplane tickets) have brought about better accessibility to air transport (Dobruszkes et al., 2016). The most visible changes in the offer of air travel are particularly present in the high season in tourism (July and August). The changes are demonstrated by the considerable growth of airplane tickets (with the highest prices being from June to August and in December), as well as by the higher frequency of flights being offered. A characteristic trait in the seasonality of the offer of flights in Central Europe is the noticeably higher offer of flights in the summer months, which connect metropolitan areas with touristic destinations in Southern Europe and North Africa (Peeters et al., 2007). A second important feature is that a substantial part of flight offers during the summer season is served by charter and low-cost carriers.

\section{The recent development of air transport in Central Europe}

Air transport in Central European countries has witnessed very specific developments. The full deregulation of air transport in the region did not occur until 2004, the year that ten, for the most part post-socialist, countries joined the European Union. This was the end of the stage of liberalisation and deregulation of air transport in Central Europe, as free air space expanded from Western Europe. It is interesting that changes in the spatial configuration of air transport took a very short time to complete. Accession to the European Union and the corresponding reorganisation of air transport delivered an abrupt development of new phenomena: expansion of LCCs and the development of secondary airports (Graham and Shaw, 2008; Seidenglanz, 2011). Although individual airlines adopted various strategies in their expansion to the deregulated space of Central Europe, the region on the whole demonstrated the building of better connections of its airports to airports in Western Europe (Gábor, 2009). Charter flights are still typical for air transport in Central Europe (mainly for the eastern part) and their share of the market is still relatively high. In comparison, the importance of charter flights declined in Western Europe under the pressure of LCCs (Dobruszkes, 2009). Similar to most regions in Europe, air transport in Central Europe was hit by the economic crisis after 2008. A principal result was the advent of fiercer competition between individual airlines (alliances and LCCs), the reduction in the number of regular and charter flights, and the bankruptcy of several airlines (see further: Dobruszkes and Van Hamme, 2011; Oprea, 2010).

A major change in the development of air travel in Central Europe was the expansion of LCCs. The most important changes with LCCs included the better accessibility of air transport in the region and changes in the organisation of airlines (see also: Graham and Dennis, 2010). This can also be documented by the offer of seat capacities of flights in Central Europe (Tab. 1). This table clearly indicates that Wizz Air and Ryanair, two LCCs, hold the second and third positions, respectively, of the 10 largest airlines offering seating capacity in Central Europe. This is also supported by the fact that, while in 2000 the seating capacity offered by LCCs were unimportant, the seating capacity offered by these companies in 2009 amounted to nearly half of the capacity offered in Europe overall (Seidenglanz, 2010). In this respect, Turnock (2003) states that the expansion of LCCs and the general growth of importance in air transport in Central and Eastern Europe, are some of the most important signs of the post-socialist transformation of these countries. 


\begin{tabular}{clccc}
\hline Rank & Operating Airline & Available Seats & \% Share & 2012/2013 Change (\%) \\
\hline 1 & Aeroflot & $18,483,574$ & 13.7 & 19.2 \\
2 & Wizz Air & $7,582,440$ & 5.6 & 8.3 \\
3 & Ryanair & $7,492,527$ & 5.6 & 19.3 \\
4 & UTair & $7,237,252$ & 5.4 & 3.0 \\
5 & Transaero Airlines & $7,214,813$ & 5.3 & 24.0 \\
6 & S7 Airlines & $6,332,116$ & 4.7 & 15.3 \\
7 & Rossiya Airlines & $4,573,038$ & 3.4 & 15.2 \\
8 & Lufthansa & $3,647,713$ & 2.7 & 7.2 \\
9 & LOT Polish Airlines & $3,429,724$ & 2.5 & -9.9 \\
10 & Ukraine International Airlines & $3,313,129$ & 2.5 & 101.0 \\
\hline
\end{tabular}

Tab. 1: Available seat capacity within and from Central and Eastern Europe in 2013

Source: OAG aviation, www.oag.com

Dramatic changes in the development in air transport are quite typical for former socialist countries. Data provided by EUROSTAT indicates that the position of Central Europe has relatively improved in terms of the number of passengers travelling by air. While in 2004, Central Europe registered less than $19.7 \%$ of the entire European air transport market, the share of Central Europe for 2014 grew to $20.6 \%$. The entire Central European region has reported changes in the period 2004-2014 that were better than the average in the development of the number of passengers travelling by air. Of course, the leading market in Central Europe is Germany with over 186 million passengers transported by air in 2014 . The number of people carried by air transport grew in Germany constantly from 2003, although it was temporary influenced by the economic crises in 2008 and 2009 . Relatively, the largest growth in the number of passengers, however, was recorded in Poland where the value has more than quadrupled over 10 years (Fig. 1). Tłoczyński (2016) states that the principal reasons for such growth includes the expansion of LCCs in Poland (especially Ryanair, easyJet, Wizz Air) and the relative size of Poland's market, including the potential for domestic flights.

\section{Data and Methods}

A vast database of historical data from the flightstats.com server is used for the analysis of seasonality in the offer of air transport in Central Europe. Information on air transport was collated from the on-line offer of flights from the airports' official statistics. Therefore, information is used on the number of flights offered, but they may differ in capacity. As data on the number of passengers boarding flights on individual lines is not available (it represents the strategies and business secrets of the carriers), some authors use the data on available seat capacity (e.g. Suau-Sanchez and Burghouwt, 2011). Basically, this is due to the differences in the capacity of various airplane types; however, the offered seating capacity and the offered number of flights show a very high rate of correlation. Thus we used the data on the number of flights as it is sufficient for the purposes of this research. All the data used refer to 2014. Given the time constraints of data collection, three days were monitored in each month (Tuesdays, Saturdays and Sundays). Special attention was given to days preceding important holidays (Easter, Christmas, and days in the summer holiday period), as elevated general demand for flight tickets is assumed, which affects both the price and offer of flights.

One crucial question for the entire research project is the selection of monitored airports. We are focussed on an analysis of the seasonality of flight offers with respect to airports in the Central European region. The delimitation of Central Europe is quite a difficult question because of different understandings. We presume that for the research, it may be interesting to hypothesize that Central Europe can be seen as a bridge between Eastern and Western Europe

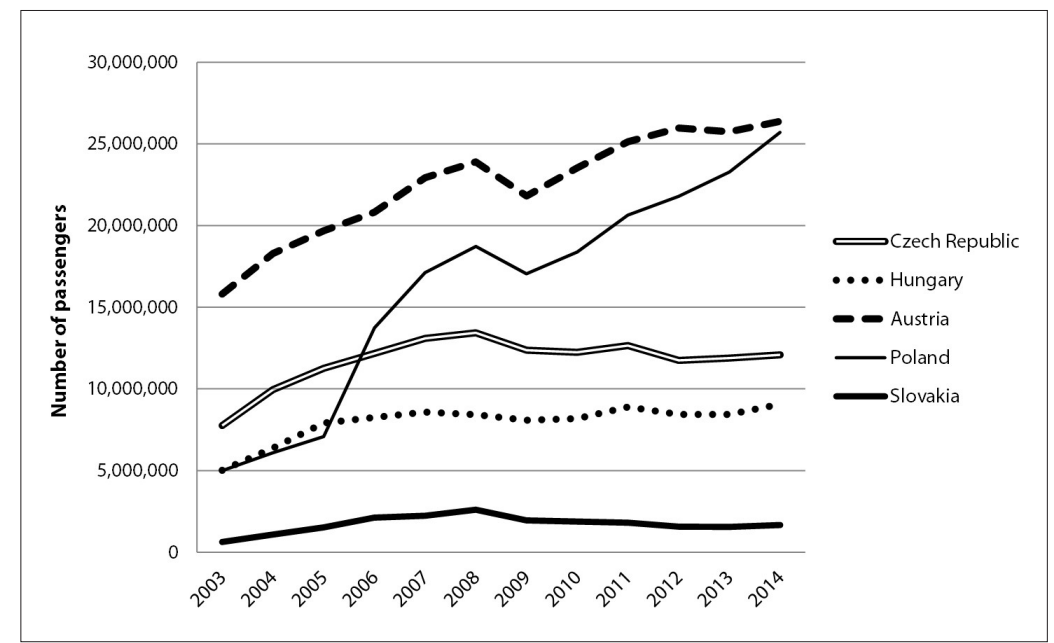

Fig. 1: Number of passengers carried by air transport in Central Europe (except Germany). Source: Eurostat - Transport Statistics (http://ec.europa.eu/eurostat) 
(see for example, Bláha and Nováček, 2016). We understand Central Europe as a set of countries with common historical, geographical and cultural features, and represent this as Germany, Austria, the Czech Republic, Poland, Hungary and Slovakia. The airports were selected purposively, as the focus was on major airports acting as international hubs (Vienna, Prague and Warsaw) and minor airports providing connection to the hubs (Debrecen, Bratislava, RostockLaage, Pardubice, Brno, Frankfurt-Hahn and Salzburg). Some important hubs are missing (e.g. Budapest), but the purpose of the research is to analyse the fluctuation in flight offers for different types of airports.

Although selection is always subjective, the authors are convinced it is also sufficiently representative. Airports from all Central European states are represented, including the more developed states (Germany and Austria) with a relatively strong tradition of air transport, and the less developed states (the Czech Republic, Poland, Slovakia and Hungary). The purpose was to identify which airports focused on seasonal flights and which had an offer of flights that was more balanced throughout the year. An integral part of the design was also an analysis of the presence of major airlines (network carriers) and LCCs offering individual flights from the airports. This information is crucial to understanding the importance of airports in the Central European air transport system, as well as for the interpretation of the findings. The different spatial strategies of LCCs and network carriers have been pointed out in previous studies (Francis et al., 2006). The final monitored parameters for the selected Central European airports are the changes in the accessibility of final destinations from the airports, inside and outside the high seasons. Changes in accessibility receive adequate attention because charter flights are often offered in the summer months; these flights in many cases expand the accessibility of the final destination.

The first part of the analysis primarily focuses on the basic structural characteristics of the airports from the perspective of an individual flight offer, the structure of the carriers and the development of their seasonal fluctuations. Subsequently, the analysis of seasonal changes in the availability of final destinations from the airports is presented. The results of these partial analyses are seen in a typology of the monitored airports from the perspective of the offered flights and the type of carriers, using the Ossan Triangle.

\section{The seasonality of flight offers at selected airports}

Seasonal fluctuation in the offer of air transport is a natural and frequent phenomenon, as it is affected by the logical higher demand for air transport by tourists in the summer months. There may be great differences in seasonality, however, when one takes into account individual airports. This also indicates the orientation of the airports and carriers in specific segments of the customer markets of air transport. A major research question is thus whether seasonal fluctuation is typical for smaller airports or for the airline hubs. A subsequent question is whether a higher seasonality rate is primarily typical for the LCCs or, conversely, for traditional network airlines. Hence, we have also included an analysis of seasonality expressed as a function of the type of carrier.

The monitored airports clearly differ in the number of flights they offer, as well as in the number of carriers as classified above. The basic specifications of the airports are shown in Table 2 and Figure 2. The table indicates that the highest number of flights throughout the year is offered in Vienna, Warsaw and Prague. For 2014, the highest number of departures was offered by Vienna, with nearly 23 thousand flights during the specified period (see section 4). The number of flights offered by Prague and Warsaw is approximately 10 thousand per year. All three airports can be considered major international hubs with a wide offer of flights and available final destinations, and they are primarily served by major airlines (Sellner and Nagl, 2010). From the group of analysed airports, Salzburg and Frankfurt-Hahn can be classified as mid-size, with 1,800 and 900 departures per year, respectively. On the other hand, smaller airports are located in Brno, Pardubice, Bratislava, Debrecen and Rostock. What matters, though, is that all of them do possess specific positions in the Central European system of air transport. The key determinants of their size/importance are especially the population size of the regions, the position of the airport in the air transport system, the accessibility of airports, etc.

The monitored airports are also specific in terms of the seasonality in the number of flights they offer (Figs 2 and 3) and this may have various manifestations. The generally accepted notion that the highest number of flights can be recorded particularly in the summer months can be confirmed only from some of the airports. "Typical" seasonal development of the number of flights offered (with the peak in the summer months and a rather constant offer of flights for the rest of the year) is seen in the major airports of Central Europe (Vienna, Prague and Warsaw). It is the result of a combination of the offer of air transport (network carriers), charter flights related to the tourist season, and the higher frequency of flights of LCCs. Prague Airport, for example, offers a rather balanced number of flights throughout the year at approximately 700 flights (during the monitored period); however, the number of flights offered in the peak of the tourist season approaches 1,000. Vienna Airport shows similar parameters (maximum number of flights from June to September), as well as Warsaw (the maximum being available from June to October). All three of these airports present the passengers with a wide offer of destinations in Europe and worldwide (see below). It is worth noting, however, that the number of flights offered in Central Europe's airports somewhat fluctuates even in the peak of the tourist season. Another interesting fact is that,

\begin{tabular}{lcrc}
\hline \multicolumn{1}{c}{ Airport } & IATA Code & Passengers & $\begin{array}{c}\text { Flight } \\
\text { operations }\end{array}$ \\
\hline Vienna & VIE & $22,483,158$ & 230,781 \\
Prague & PRG & $11,149,926$ & 125,437 \\
Warsaw & WAW & $10,590,473$ & 121,913 \\
Frankfurt-Hahn & HHN & $2,447,140$ & 22,152 \\
Salzburg & SZG & $1,819,520$ & 19,335 \\
Bratislava & BTS & $1,355,625$ & 21,481 \\
Brno & BRQ & 486,134 & 32,216 \\
Pardubice & PED & 150,056 & 2,188 \\
Rostock-Laage & RLG & 169,946 & no data \\
Debrecen & DEB & 172,219 & 1,350 \\
\hline
\end{tabular}

Tab. 2: Basic statistics of selected airports in 2014 Source: Annual Reports of Airports 


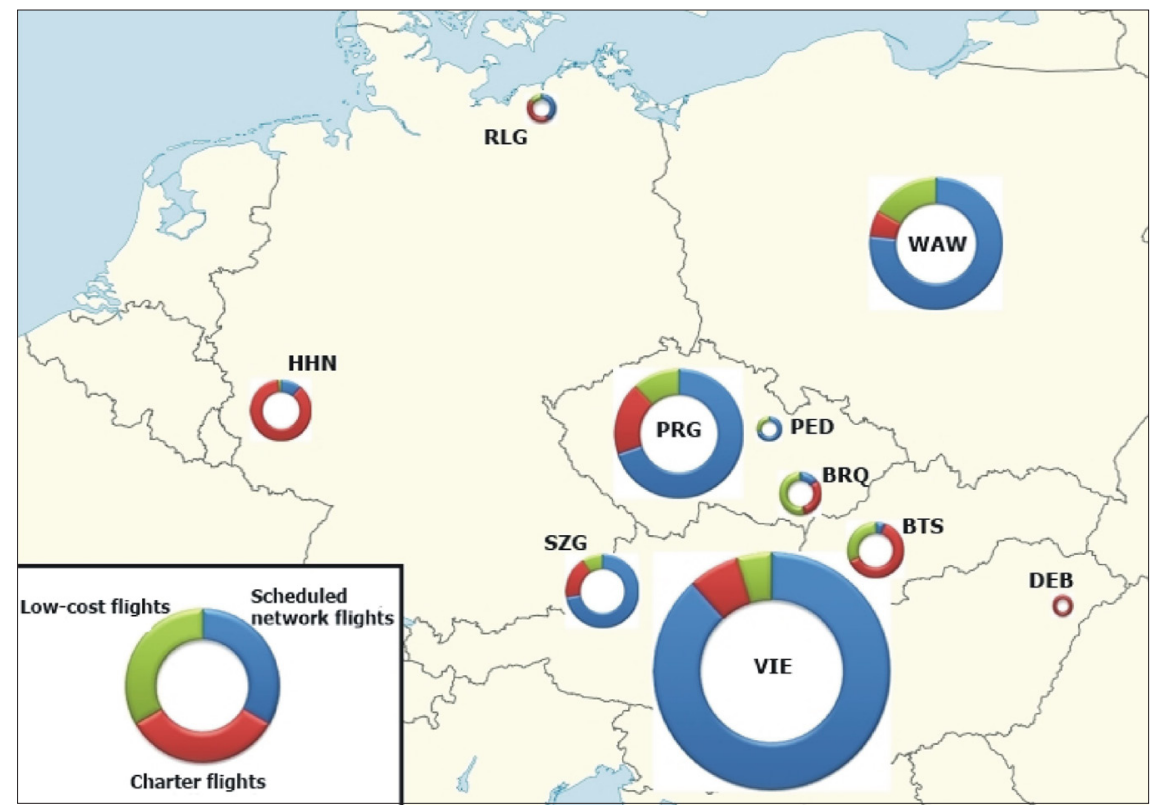

Fig. 2: Structure of offered flights for the selected airports in 2014

Sources: Historical Flight Status (flightstats.com); authors' calculations

compared to earlier studies (e.g. Reichard, 1988) the peak of the tourist season extends to September, even into October. Such a development is probably related to the changes in the offer of tourist destinations and travel agencies, who are using these favourable months to promote cheaper holidays in Europe and other nearby destinations, i.e. last-minute holidays. All of these large airports are mainly served by scheduled network flights, while the share of low-cost and charter flights is rather low.

In a quite different and largely heterogeneous group are the smaller of the monitored airports. The heterogeneity is in most cases demonstrated as seasonality in the offers of the airlines and, of course, in the structure of offered flights. A more apparent seasonality in the offers of airlines is especially shown by Brno Airport. This airport recorded, in 2014, a record-breaking increase in passengers using both charter lines, most often served by a Travel Service carrier (to Antalya, Burgas, Heraklion) and in regular lines to Stansted (by Ryanair) and Luton (Wizz Air). A similar fluctuation in the offer of flights in the summer is seen at Frankfurt-Hahn Airport. Although rather distant, the airport primarily serves as an alternative to the busy Frankfurt International airport (IATA: FRA). It is serviced, for the most part, by LCCs (Ryanair, Wizz Air, SunExpress). Considering its position, the airport focuses on offering airlines to tourist destinations in East and Southern Europe and North Africa. Those destinations are especially popular in the peak tourist season in the summer months.

A less dominant seasonality in the offer of flights is seen in the case of Bratislava Airport. Although the airport is often referred to as secondary to Vienna, it recorded in 2014 an approximate 5\% decrease in the number of checkedin passengers; this was attributed to the cancellation of the lines to Bristol (Ryanair), Oslo and Copenhagen (Norwegian), in particular. Other negative factors were the European Union's sanctions against Russia (the number of checked-in passengers dropped to $50 \%$ of the 2013 numbers), and the bankruptcy of the Air Onix airline from Ukraine after military conflicts broke out in the eastern part of that country. Similar to the case of Brno Airport, moreover, the year 2014 did not witness an increase in the number of passengers travelling on non-regular lines (especially to Bulgaria and Greece). Salzburg Airport shows a similar progress of seasonality in the offer of flights. This airport has a strong preference for destinations in Western Europe (Germany, the UK, the Netherlands); however, in the summer months it also offers frequent flights to Turkey, Spain and Egypt. Charter flights amount to over one-quarter of all aviation activity there. Most of these airports are dependent on LCCs and charter flights as shown in Figure 2. Low-cost and charter flights are crucial for their viability. The vast majority of flights are carried by low-cost and charter flights, and this is typical for example for airports in Brno and Bratislava, in contrast to the dominance of scheduled network flights at the Vienna airport. These airports thus serve as complementary airports to the Vienna hub airport, but they mostly offer cheaper flights in the summer seasons.

The last group of airports are typically small and they have a specific seasonal offer of airlines. An example may be the airport Rostock-Laage, which is usually used for domestic German flights (Cologne, Bonn, Munich, Stuttgart). The impact of the summer season is very small as the airport registers seasonal summer flights rather scarcely and in the form of charter flights (Mallorca, Crete, Rhodes, Varna or Burgas). Similarly, Debrecen Airport, which predominantly serves Wizz Air flights, has only a minor increase in the number of offered flights in the summer months. This airport focuses on lines connecting destinations in Western and Southern Europe (Luton, Eindhoven, Milano, etc.). Only rarely does it offer seasonal flights to tourist destinations (Korfu, Antalya). Pardubice Airport, as in the case of Bratislava, was seriously struck in 2014 by the sanctions the European Union adopted against Russia (continuously from March 2014) as it was considerably oriented to a Russian clientele. Although there had been a minor increase in the number of passengers arriving from Russia in 2014 compared to 2013 (97 thousand in 2013, 98 thousand in 2014), the number of passengers on charter flights was reduced considerably (54 thousand in 2013, 24 thousand 


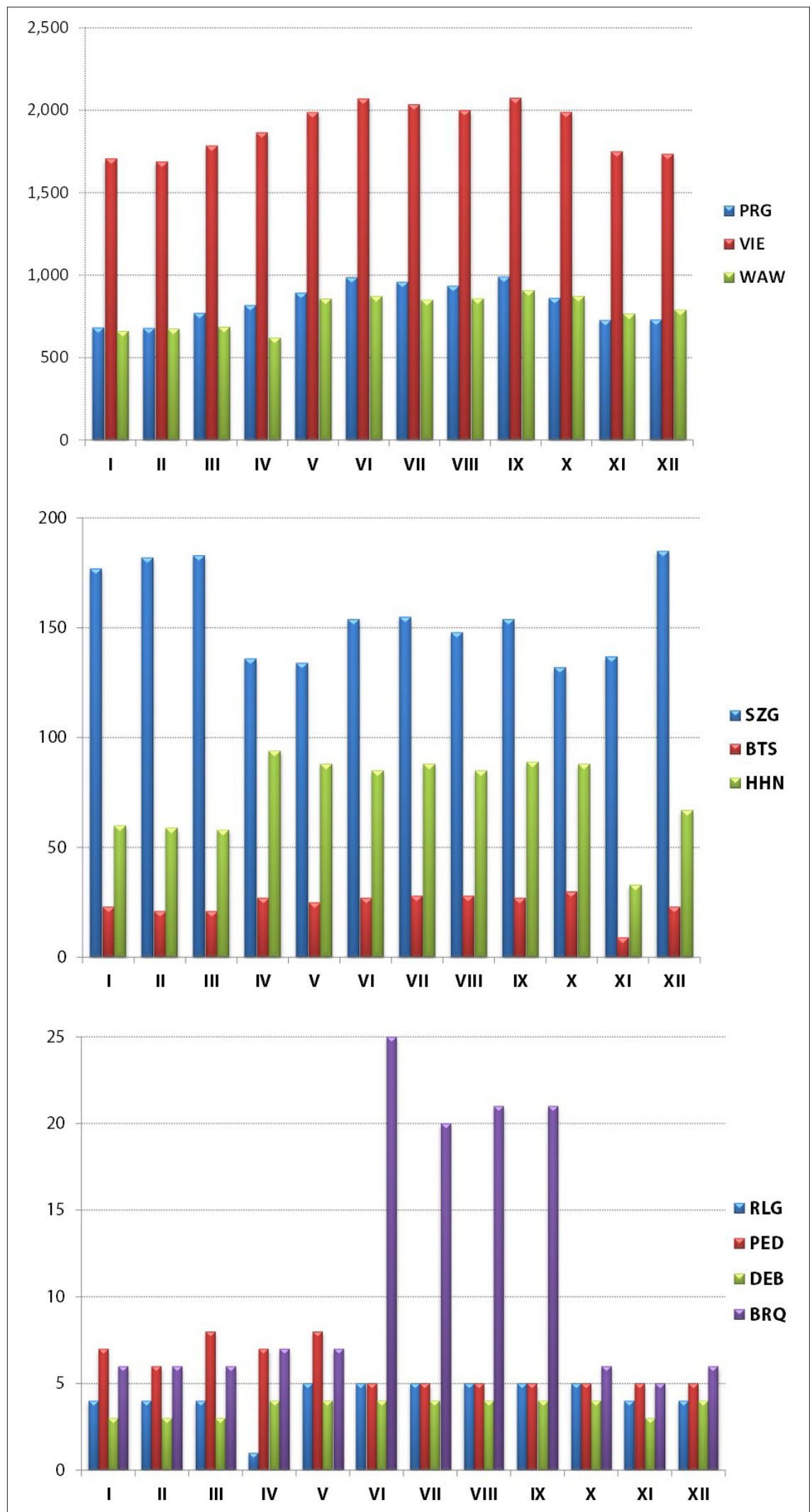

Fig. 3: Number of flight offers in the monitored airports during the year 2014

Sources: Historical Flight Status (flightstats.com); authors' calculations

in 2014). Another negative influence was the termination of the Kogalymavia airline and the reduction in the number of flights from Moscow, Saint Petersburg and Yekaterinburg (Transaero Airlines). Based on this historic development, the airport decided to predominantly focus on flights to traditional tourist destinations (Rhodos, Burgas, Podgorica).

\section{Seasonal changes in the accessibility of destinations}

We consider seasonal changes in the accessibility of destinations as another key manifestation of the different spatial strategies employed by individual carriers and 


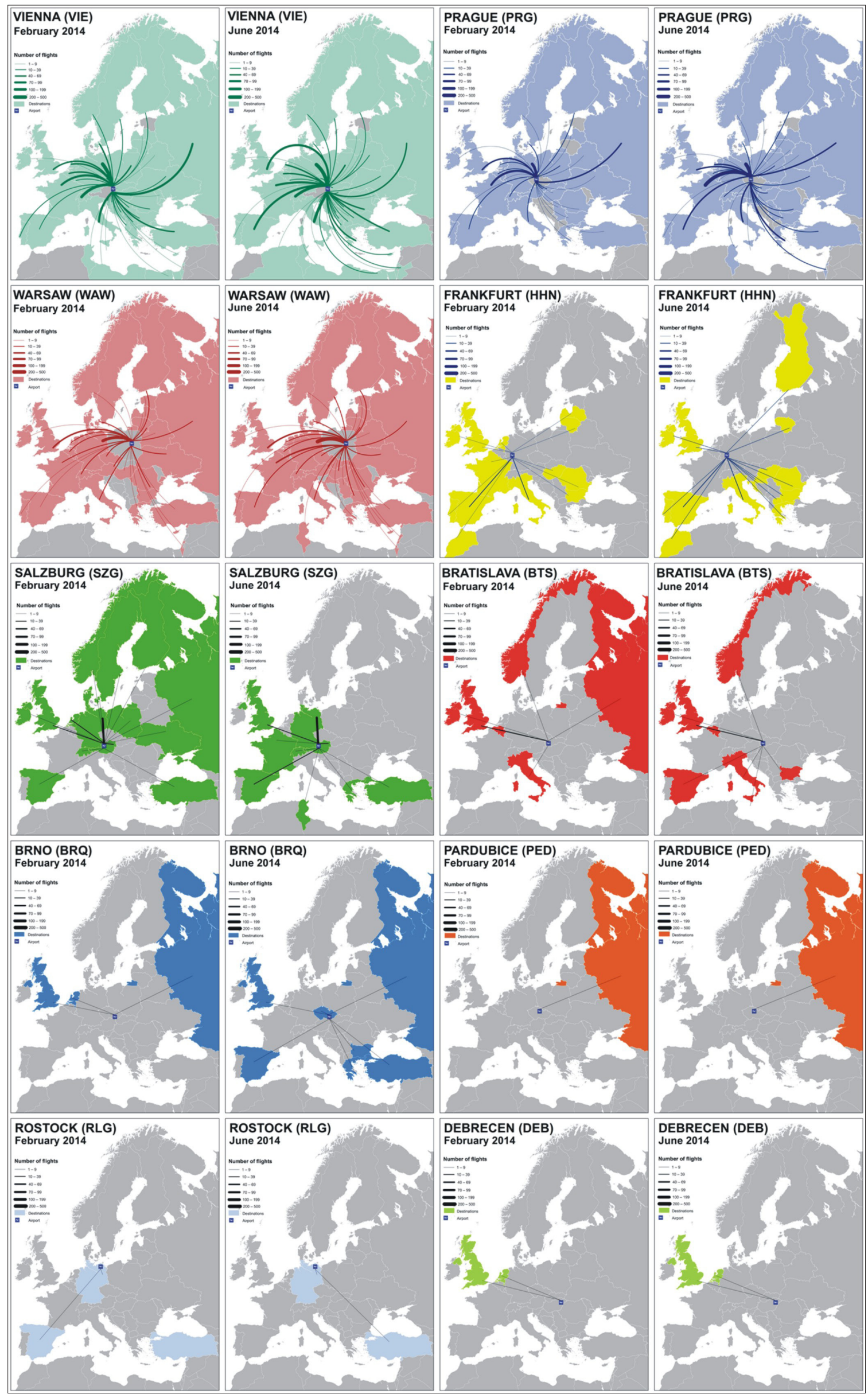

Fig. 4: Accessible destinations from the monitored airports during the year 2014

Sources: Historical Flight Status (flightstats.com), authors' calculations 
airports. Given the derivations from the major fluctuations in the offer of air transport demonstrated above, assumptions can be made about the considerable changes in the accessibility of destinations occurring during the year. It can also be assumed that the peak tourist season period sees a certain intensification of air transport between the monitored airports in Central Europe with destinations in Southern Europe and North Africa. Those regions represent traditional tourist destinations for the inhabitants of Central European countries. Moreover, users of air transport also consider the accessibility of final destinations as one of the principal attributes of the attractiveness of an airport from their point of view.

Changes in the accessibility of final destinations are also largely affected by the size and importance of the monitored airport, or by the orientation of key airline carriers on specific segments of their customers. Therefore, a rather stable network of accessible destinations is, again, seen in the major airports in Vienna, Prague and Warsaw. Disregarding very minor exceptions, it can be stated that all of the airports mentioned above offer flights to all countries in Europe. This also attests to their importance in the Central European region as well as to their important position in air transport in Europe. The share of non-European flights is rather low: $13.1 \%, 12.9 \%$ and $8.8 \%$ in Prague, Vienna and Warsaw, respectively. This segment of flights was clearly dominated by flights to Asian destinations (Turkey, Thailand, the USA and Japan). As far as flights within Europe are concerned, a larger share was taken by flights directed to Germany, the UK, Russia, France and Italy. This is logical as those regions represent important resources and destinations for both business and pleasure trips for Central European travellers.

Changes in the accessibility of final destinations between the peak (June 2014) and off-peak (February 2014) tourist seasons are shown in Figure 4. It is clear that the accessibility of final destinations in Vienna, Prague and Warsaw airports show little variation during the season; nonetheless, an observation can be made about the considerable increase in the number of flights to Southern and South-Eastern Europe in June 2014. Greece is a fitting example of the situation. Vienna Airport prepared the departures for a total of 9 airplanes in February 2014, while the number grew to 61 in June 2014. The largest fluctuations from the airports in Prague and Warsaw during the season, however, are typical for flights to Croatia, Greece and Bulgaria. For a very long time, those countries have been popular summer holiday destinations. An interesting fact is that, at the same time, concerning flights to destinations in Western and Southern Europe in the summer. The largest increments are then seen in the connections between large cities in Central Europe and Turkey, Tunisia and Egypt. Those trends are very closely related to the changes in demand for key tourist destinations. Vice versa, relatively the smallest seasonal differences in the offer are related to the flights bound for Northern Europe. There are rather prominent differences in the connections with Russia, with the peak being presently in the summer.

The highly heterogeneous set of smaller airports in Central Europe, then, show some large differences in the offer of final destinations during the period of interest. Some of the airports have also shown that inside the peak tourist season, they offer a lower number of flights (see above) together with fewer destinations. Salzburg Airport documents this situation reliably. This airport proves that there are major changes in the offer of accessible destinations in the summer months.
In 2014, the majority of flights departed for Germany, Austria, the UK and the Netherlands. The airport also had a rather intensive exchange with Norway, Sweden, Russia and Spain. For the month of June 2014, on the other hand, there was a major re-orientation of flights. Germany remained the most intensive country for destinations, with major improvements in connections with Spain (especially the Canary Islands), Turkey and Greece. But there was also some limitation on flights to Northern Europe and other regions. Disregarding certain exceptions (Debrecen and Pardubice), observations can be made about the "traditional" East-West orientation of flights (Dobruzskes, 2009) changing, in the summer months, into an orientation towards Southern and SouthEastern Europe, Turkey and North Africa (Egypt, Tunisia). The specific examples of Debrecen and Pardubice airports in 2014 basically showed a unilateral orientation to the UK and the Netherlands (Debrecen) or Russia (Pardubice). It can also be assumed that for the summer season of 2014, the directional orientation of charter flights was affected by the sanctions imposed by the European Union on Russia, as mentioned above.

\section{A typology of airports based on flight offers}

This final part of the assessment of airports in Central Europe presents a typology of the airports based on the offer of air transport. Previously, we have demonstrated that the chosen airports constitute a largely heterogeneous group, with various sizes, offers of final destinations, seasonal fluctuations, etc. A typology of these airports has been established using the Ossan triangle: based on the orientation of flights, the share of LCCs, and the number of airlines. The purpose of the typology is to establish the principles and specifics of the airports in terms of orientation to their customer pools.

The different strategies and foci of individual airports with respect to their customer pools can be documented using Figure 5, which clearly shows the principal characteristics of the monitored airports in terms of the directional orientation of flights. A striking feature is the quite balanced positions of the three major airports (Vienna, Prague and Warsaw). It is assumed that the airports have a similar focus in terms of the directional orientation of flights, which basically makes them direct competitors. As traditional network carriers primarily concentrate there, these airports are especially oriented on connections to major hubs in Western Europe (London, Paris, Frankfurtam-Main and Amsterdam), which act as changing points for connections from Central Europe with destinations outside Europe (especially North America and Asia).

The share of LCCs fluctuates from 10 to $20 \%$. Therefore, the airports in Vienna, Prague and Warsaw often act as Central Europe's sub-hubs for connections to Western Europe. At the same time, they represent important locations for air transport within Central Europe (from 35 to $50 \%$ of flights). The share of flights outside Europe is rather low in this respect (approximately 15\%); the primary cause is the necessity to change flights in any of Central Europe's hubs. An equivalent model applies to Salzburg Airport which shows similar data in directional orientation of flights while displaying a higher rate of flights within Central Europe (nearly $72 \%$ ). This is especially attributable to the fact that it is Austria's second largest airport, which gives it an important position in domestic transport. Therefore, the most populated flights are bound to Vienna, Frankfurt, Zurich and Düsseldorf. 


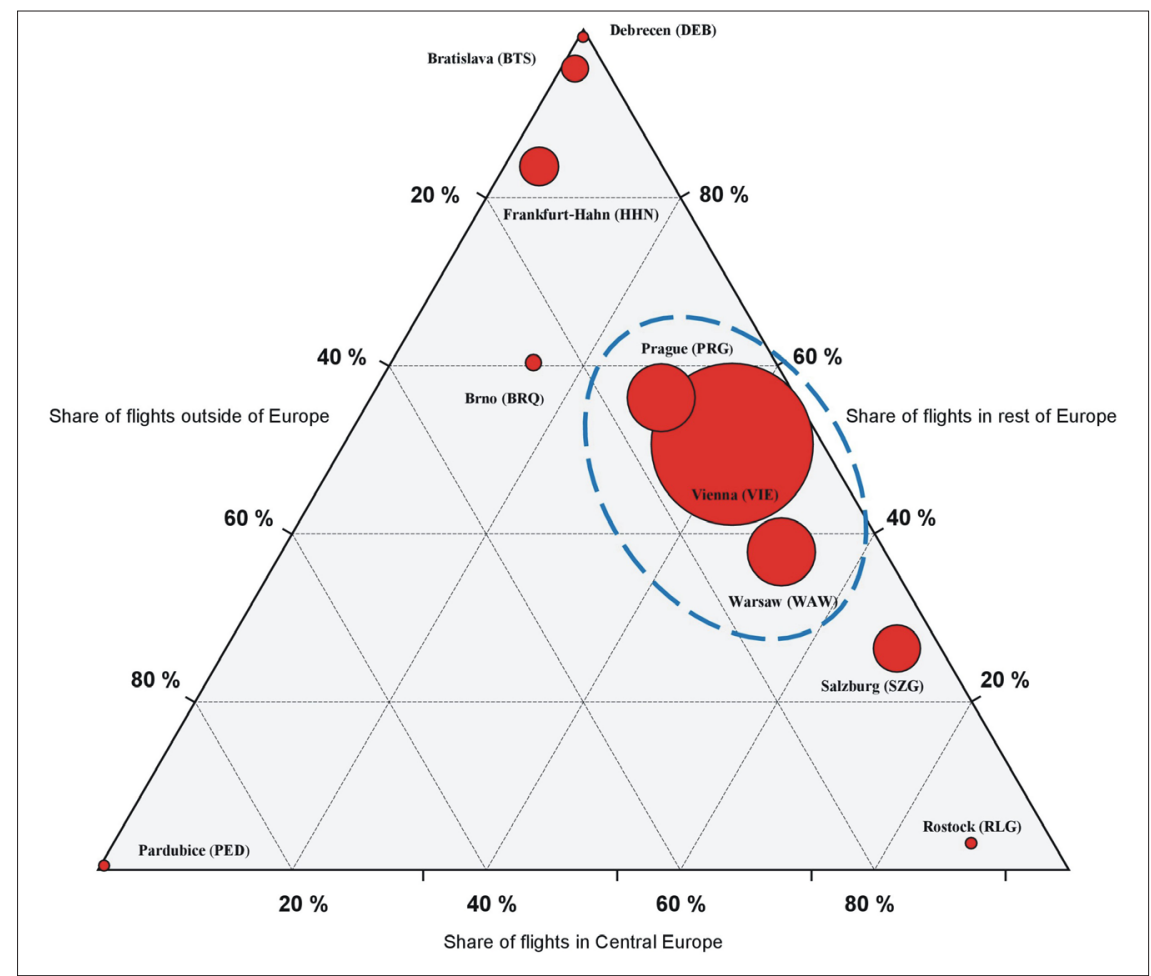

Fig. 5: Typology of the monitored airports using the Ossan triangle Sources: Historical Flight Status (flightstats.com), authors' calculations

The remaining airports represent a highly heterogeneous group of airports with a very specific position within the air transport system of Europe. This is documented by their varying characteristics in the directional orientation of flights. The heterogeneity of the smaller airports results from a number of underlying causes: the size of the airport, their importance in air transport in Europe, the proximity to the nearest major airports, the position of the airport, and the type of carriers operating from the airport. Pardubice serves as an illustration of an airport that was solely oriented on flights to/from Russia, even in 2014 During the year, it did not offer any other destinations, which manifested itself negatively in the reduction of total passenger count in 2014. An interesting point is that this airport was only served by network carriers.

On the other hand, Debrecen in that year focused exclusively on securing air lines with the UK and the Netherlands. Bratislava Airport showed similar results, but its primary benefit is its proximity to Vienna Airport and the frequent bus lines between the two. That is why Bratislava tends to be typically serviced by LCCs and charter carriers (their share in the overall number of flights amounts to over 90\%). They especially provide flights to Western Europe. Moreover, in the summer months a higher number of flights (especially charter flights) to destinations in Southern (Spain, Italy) and South-Eastern Europe (Bulgaria) are registered. As in the previous case, the evidence suggests that this airport only offers a small percentage of flights bound for Eastern European destinations (less than 2\%). This is caused by the relative proximity and competition of other types of transport (bus and railway), which are on a very good level in most of these countries (see discussion in Pucher, 1999). Different conditions apply to Frankfurt-Hahn, which also offers a minimum share of flights to Central Europe (only the lines to Hungary operated by Wizz Air). This airport serves as an alternative airport with a rather high number of final destinations. Specifically in the summer months, a large proportion of the flights are bound for Spain, Portugal and Italy. In a rather independent category is Brno Airport which especially focuses on destinations in Western Europe and Russia. A quite different profile is that of Rostock-Laage airport, which, unlike the other researched airports, focuses on connections to other German airports to provide domestic travel. The results of the analyses on the typology of the airports in terms of the offer of flights show considerable correspondence, as well as differences between the airports. They are subject to a number of factors which are dominated by the position of the airport in the air transport system, geopolitical positions, the specifics of the carriers, etc., as indicated above. These factors should be addressed by further research.

\section{Conclusions}

Central Europe has a very specific position in the European system of air transport. Some relatively unique reasons for this are the integration of former socialist countries into the single, liberalised and deregulated European airline market, and the building of new connections with Western Europe. These changes, initiated in 2004, have had a major impact on the position of air transport in the region. The findings of this study show that the former socialist countries of Central Europe have established very intensive connections with Western Europe by frequent air transport, which promotes further social, economic and cultural integration with the West. Evidence also suggests that the spatial configuration of flights from Central Europe is primarily westbound. The East, and especially Russia, is also an important market. Although these countries are mainly oriented to western markets, they are also strongly connected with Russia: in particular, some small airports are dependent on customers from/to Russia. A number of airports in Central Europe showed a very strong orientation on customers from the East in 2014, and the East-West direction is most important 
in the current configuration of flights from Central Europe. This clear orientation, however, does change in a number of respects during the peak tourist season in the summer months. It is logically caused by the higher demand for tourist destinations in Southern and South-Eastern Europe, North Africa (Egypt, Tunisia) and the Near East (primarily Turkey). Therefore, many airports in Central Europe are oriented also in a North-South direction during the summer season. This becomes obvious especially in smaller airports with a higher rate of LCCs and charter flights.

As shown above, charter flights are still typical for the Central European region. Their role is not replaceable. Their importance can be seen mainly during the summer season, when providing cheaper alternatives for connections of Central European countries with popular holiday destinations in Southern Europe, the Near East and North Africa. The strong position of charter flights can be seen mainly by airports in the eastern part of Central Europe (especially in the Czech Republic and Poland). Another factor that needs to be added is the rather strong orientation of large hub airports on frequent connections with South-Eastern Europe. On the contrary, connections to Northern Europe are rather scarce. The north of the continent has stronger economic and cultural connections to Western Europe; however, it represents an area of potential expansion for airlines. Moreover, Northern Europe is not a typical destination for spending summer holidays for customers from the Central Europe - it is quite an expensive destination.

Smaller airports show a stronger specialisation in selected destinations and/or specific segments of the customer market (e.g. charter flights), etc. A number of airports depend on the presence of one or more carriers who, for the most part, define the spatial orientation of flights departing from that airport. A good example is Debrecen Airport, which is predominantly served by Wizz Air. In general, it can be observed that smaller regional airports do establish a highly heterogeneous group of airports in many ways. Some of the airports benefit from their proximity to important European hubs and from the accelerated importance to LCCs (e.g. Bratislava), others serve as secondary airports for domestic flights (e.g. Rostock-Laage). Airports in Bratislava and Brno are strongly dependent on charter flights, and they profit especially from proximity to the Vienna hub airport. They serve as secondary airports with rather complementary functions. From the issue of seasonality affecting the offer of flights, this is a rather heterogeneous group: some of the airports exhibit a clear orientation towards the peak tourist season, while others show nearly no impact of the summer.

The deregulation and liberalisation of air transport, which appeared after a number of the East European countries joined the EU, has basically changed the map of air transport. Since 2004, the concentration of airlines, the establishment of hubs, the optimisation of airlines and transition to the huband-spoke arrangements, are all factors that have delivered a considerable amount of asymmetry to the air transport network. The asymmetry is logical in many respects as the hubs have become natural centres of air transport with high potential for development. The exclusive hierarchy position of all major airports considered here (Vienna, Prague and Warsaw) deserves a positive assessment as they became, over time, major centres of air transport of European importance. On the other hand, it was the establishment of the main European hubs (Amsterdam, London, Paris, Madrid, etc.) as important global air connections which have considerably limited the position of Central Europe. Hence, the monitored airports have a very low share of flights outside Europe (see discussions in Thompson, 2002; Dobruszkes, 2006). There is some potential for development, however, through the identification of new destinations, especially in Asia. One example is the expansion of Hainan Airlines to establish connections between Prague and Beijing. The strong hierarchy arrangement of air transport in Central Europe, to a certain extent, defines the potential of development of other airports. In order to protect themselves from the competition of major airlines concentrated in the hubs, smaller carriers often seek smaller airports, usually with a strong orientation on specific segments of the customer market.

One interesting question that has so far received little attention in the research literature is the impact of the European Union's sanctions against Russia on air transport in Central Europe. As mentioned above, Russia was an important area on which a number of rather small airports in Central Europe focused prior to 2014. The imposition of sanctions in March 2014 considerably limited the opportunities to travel. A number of airports focusing on Russian clients experienced serious problems. Preliminary observations show that individual airports often adopted various strategies to mitigate the impact of sanctions on Russia and the reduction of checked-in passengers arriving from Russia and the Far East. Those defensive strategies should be examined by research in the future, as they quite clearly point to the actual dependence of air transport on political decisions.

\section{Acknowledgement}

The research was supported by the Grant Agency of University of South Bohemia (grant project GA JU, reg. No. 160/2016/S).

\section{References:}

ALDERIGHI, M., CENTO, A., NIJKAMP, P., RIETVELD, P. (2005): Network competition - the coexistence of huband-spoke and point-to-point systems. Journal of Air Transport Management, 11(5): 328-334.

BLÁHA, J. D., NOVÁČEK, A. (2016): The Perception and Delimitation of Central Europe in the Mental Maps of Individuals from Selected European Countries. Mitteilungen der Österreichischen Geographischen Gesellschaft. Band 158, in print.

BUTTON, K., HAYNES, K., STOUGH, R. (1998): Flying into the future: air transport policy in the European Union. Edward Elgar Publishing, Cheltenham.

BURGHOUWT, G. (2007): Airline Network Development in Europe and its Implications for Airport Planning. London, Ashgate.

BURGHOUWT, G., HUYS, M. (2003): Deregulation and the Consequences for Airport Planning in Europe. disP - The Planning Review, 39: 37-45.

COOK, G., GOODWIN, J. (2008): A Comparison of Hub-andSpoke and Point-to-Point Systems. Journal of Aviation/ Aerospace Education \& Research, 17(2): 51-60.

DEBBAGE, K. (1994): The international airline industry: globalization, regulation and strategic alliances. Journal of Transport Geography, 2(3): 190-203.

DERRUDER, B., WITLOX F. (2008): Mapping world city networks through airline flows: context, relevance, and problems. Journal of Transport Geography, 16(5): 305-312. 
DOBRUSZKES, F. (2006): An analysis of European lowcost airlines and their networks. Journal of Transport Geography, 14(4): 249-264.

DOBRUSZKES, F. (2009): New Europe, new low-cost air services. Journal of Transport Geography, 17(6): 423-432.

DOBRUSZKES, F., VAN HAMME, G. (2011): The impact of current economic crisis on the geography of air transport volumes: An empirical analysis. Journal of Transport Geography, 19(6): 1387-1398.

DOBRUSZKES, F., MONDOU, V., GHEDIRA, A. (2016): Assessing the impacts of aviation liberalisation on tourism: Some methodological considerations derived from the Moroccan and Tunisian cases. Journal of Transport Geography, 50(1): 115-127.

FRANCIS, G., HUMPREYS, I., ISON, S., AICKEN, M. (2006): Where next for low cost airlines? A spatial and temporal comparative study. Journal of Transport Geography, 14(2): 83-94.

GÁBOR, D. (2009): Low-cost Airlines in Europe: Network Structures After the Enlargement of the European Union. Geographica Pannonica 14(2): 49-58.

GOETZ, A., SUTTON, C. (1997): The Geography of Deregulation in the U.S. Airline Industry. Annals of the Association of American Geographers, 87(2): 238-263.

GOETZ, A., GRAHAM, B. (2004): Air transport globalization, liberalization and sustainability: post-2001 policy dynamics in the United States and Europe. Journal of Transport Geography, 12(4): 265-276.

GRAHAM, B., SHAW, J. (2008): Low-cost airlines in Europe: Reconciling liberalization and sustainability. Geoforum, 39(3): 1439-1451.

GRAHAM, A., DENNIS, N. (2010): The impact of low cost airline operations to Malta. Journal of Air Transport Management, 16(3): 127-136.

GRENČÍKOVÁ, J., KRIŽAN, F., TOLMÁČI, L. (2011): Stability and actuality of aviation networks in Bratislava and Prague. Moravian Geographical Reports, 19(1): 17-31.

IVY, R. (1995): The restructuring of air transport linkages in the new Europe. The Professional Geographer, 47(3): 280-288.

JANKIEWICZ., H., HUDEREK-GLAPSKA, S. (2016): The air transport market in Central and Eastern Europe after a decade of liberalisation - Different paths of growth. Journal of Transport Geography, 50(1): 45-56.

OPREA, M. (2010): The effects of global economic crisis on the air transport of passengers in Europe and in Romania. GeoJournal of Tourism and Geosites, 1(5): 52-61.

PAGE, S. (2005): Transport and tourism: Global perspectives. Prentice hall, Harlow.

PAPATHEODOROU, A. (2002): Civil Aviation Regimes and Leisure Tourism in Europe. Journal of Air Transport Management, 8(6): 381-388.
PEETERS, P., SZIMBA, E., DUIJNISVELD, M. (2007): Major environmental impacts of European tourist transport. Journal of Transport Geography, 15(2): 83-93.

PUCHER, J. (1999): The transformation of urban transport in the Czech Republic, 1988-1998. Transport Policy, 6(4): 225-236.

REGGIANI, A., SIGNORETTI, S., NIJKAMP, P., CENTO, A. (2009): Network Measures in Civil Air Transport: A Case Study of Lufthansa. Network, Topology, Dynamics, 613(1): 257-282.

REICHARD, H. (1988): Seasonality on air transportation demand. Flight Transportation laboratory report R88-3. Cambridge, MIT.

RODRIGUE, J. P., COMTOIS, C., SLACK, B. (2013): The Geography of Transport Systems. $3^{\text {rd }}$ Edition. New York, Routledge.

SEIDENGLANZ, D. (2008): Central Europe: Urban Typology Based on Airport Location and Accessibility. Miscellanea Geographica Universitatis Bohemiae Occidentalis, 14: 143-148.

SEIDENGLANZ, D. (2010): Air transport in Central Europe under the influence of low-cost airlines. Geography for life in $21^{\text {st }}$ Century, 523-528.

SEIDENGLANZ, D. (2011): Changes of air transport networks in Central Europe after 1990. In AAG Annual Meeting 2011, Seattle, USA.

SELLNER, R., NAGL, P. (2010): Air accessibility and growth - The economic effects of a capacity expansion at Vienna International Airport. Journal of Air Transport Management, 16(6): 325-329.

SUAU-SANCHEZ， P. ,BURGHOUWT， G. (2011): The geography of the Spanish airport system: spatial concentration and deconcentration patterns in seat capacity distribution, 2001-2008. Journal of Transport Geography, 19(2): 244-254.

THOMPSON, I. (2002): Air transport liberalisation and the development of third level airports in France. Journal of Transport Geography, 10(4): 237-285.

TŁOCZYŃSKI, D. (2016): Development Policy of Warsaw Chopin Airport in the light of the European Funds for 2014-2020. Procedia Engineering, 134: 408-414.

TURNOCK, D. (2003): The human geography of East Central Europe. Routledge, London.

WANG, J., BONILLA, D., BANISTER, D. (2016): Air deregulation in China and its impact on airline competition 1994-2012. Journal of Transport Geography, 50(1): 12-23.

WENSVEEN, J. (2007): Air Transportation: A Management Perspective. Ashgate, Aldershot.

\section{Please cite this article as:}

KRAFT, S., HAVLÍKOVÁ, D. (2016): Anytime? Anywhere? The seasonality of flight offers in Central Europe. Moravian Geographical Reports, 24(4): 26-37. Doi: 10.1515/mgr-2016-0020. 